\title{
PROLONGED EXPOSURE TO DIFFERENT TYPES OF ENERGY RESTRICTED CALCIUM DIET MODULATES THE INFLAMMATORY AND OXIDATIVE STRESS RESPONSE IN HEALTHY MALE RATS
}

\author{
SANDEEP DAS, DIPAYAN CHOUDHURI* \\ Department of Human Physiology, Reproductive Physiology and Endocrinology Laboratory, Tripura University (A Central University), \\ Agartala, Tripura, India. Email: dipayanchoudhuri@gmail.com \\ Received: 10 May 2019, Revised and Accepted: 24 June 2019
}

\section{ABSTRACT}

Objective: Emerging evidence established the role of dietary calcium in the modulation of obesity. Obesity is known to induce inflammatory and oxidative stress in adipocytes resulting in several metabolic complications. In the present study, we evaluated the role of low and high calcium diet on systemic inflammatory response and oxidative stress markers in both plasma and hepatic tissues in male rats.

Methods: A total of 30 male rats were divided into three groups and fed with control, low calcium (0.25\%), and high calcium (1.0\%) diet for 3 months. All the diets were isocaloric in nature. At the end of the treatment, all rats were sacrificed, followed by collection of blood and hepatic tissue for inflammatory, oxidative, antioxidant, and histological study.

Results: Rats fed with a low calcium diet showed a significant increase in the body weight gain, liver mass, plasma inflammatory markers C-reactive protein, interleukin-6, and tumor necrosis factor-alpha. Low calcium diet significantly increased the lipid peroxidation and protein carbonylation and decreased the superoxide dismutase and glutathione peroxidase activities in both plasma and liver. High calcium diet, on the other hand, showed the reversed effect.

Conclusion: Low calcium in the diet, along with obesity, increases the systemic inflammatory response, which in turn increases oxidative stress both in blood and hepatic tissues. This might be associated with obesity-induced hepatic disorder. High calcium in diet attenuates this effect.

Keywords: Calcium, Interleukin-6, Tumor necrosis factor- $\alpha$, Lipid peroxidation, Superoxide dismutase, Glutathione peroxidase.

(C) 2019 The Authors. Published by Innovare Academic Sciences Pvt Ltd. This is an open access article under the CC BY license (http://creativecommons. org/licenses/by/4. 0/) DOI: http://dx.doi.org/10.22159/ajpcr.2019.v12i8.34034

\section{INTRODUCTION}

Within the past few years, the structure of dietary intake and the prevalence of obesity around the developing world have been changing at a rapid pace [1]. The global prevalence of obesity is due to the rise in the availability of low-cost, high calorie, and nutrient-poor foods over the past four decades [2]. Thus, the diet seemed to be an etiological factor behind the onset of obesity. Several recent studies have identified that there exists an inverse relationship between dietary calcium intake and the mass of adipose tissue or body fat content, which in turn modulate the risk of obesity [3]. Obesity is a global health issue and associated with other metabolic diseases including dyslipidemia, insulin resistance (IR), cardiovascular dysfunction, cancer, chronic inflammation, and oxidative stress [4].

Adipose tissue acts as an endocrine organ by secreting specific hormones or adipokines, which act as messengers to distant organs including muscle, liver, and brain, to maintain the body's energy balance and metabolic health [5]. The excess accumulation of adipose tissue leads to adipocyte hypertrophy where the size of the adipocytes grows in size to accumulate the excess amount of triglycerides. These hypertrophic adipocytes play a key role behind the onset of several metabolic dysfunctions such as IR, non-alcoholic fatty liver (NAFL), and cardiovascular diseases by altering the adipokine secretions [6,7]. The increase in secretion of inflammatory markers such as tumor necrosis factor-alpha (TNF- $\alpha$ ) and interleukin-6 (IL-6) and decrease in secretion of adiponectin found to be associated with IR, inflammation and oxidative stress in the liver. These adipose-derived inflammatory molecules can induce the production of reactive oxygen species (ROS), which can promote lipid peroxidation leading to liver damage along with the decrease in hepatocyte antioxidants levels [8]. Hence, adipose tissue-derived inflammatory markers seemed to regulate oxidative stress in other metabolically active organs like liver, which in turn increases the consequences of future metabolic complications.

Our previous study showed that various types of energy-restricted calcium diet regulate the fat accumulation by regulating the lipogenesis and lipolysis pathway, which in turn regulate the size of the adipocytes leading to hypertrophy [9]. Meanwhile, some reports have suggested that calcium implementation through diet regulate insulin sensitivity as well as hepatic steatosis $[10,11]$. Therefore, in our present study, we aimed to study the prolonged effect of different types of energyrestricted calcium diet on plasma inflammatory markers and hepatic oxidative stress markers, which are closely associated with hepatic disorders.

\section{METHODS}

Animals

Thirty $(n=30)$ healthy male rats of Wistar strain (160-170 g) were used in our study. The rats were obtained from a Committee for the Purpose of Control and Supervision of Experiments on Animals (CPCSEA) registered animal supplier (Reg. No. 1443/PO/b/11/ CPCSEA) nominated by CPCSEA, Ministry of Environment and Forests Government of India. Rats were kept at our institutional animal house under a constant environmental condition having $22 \pm 2^{\circ} \mathrm{C}$ along with $12 \mathrm{~h}$ light/dark cycle. The rats were provided with balanced diet [9] and water ad libitum. The entire experiment was approved by the Institutional Animal Ethical Committee of Tripura University (Ref. No: TU/IAEC/2014/VIII/2-6 dated 12.09.2014). 


\section{Experimental design}

After 1 week of acclimatization, animals were distributed randomly into three groups of 10 animals in each group. A control diet according to AIN-93G purified diet composition fed to the first group and regarded as the control group; the second group provided with diet having a low calcium content, regarded as the low calcium group, and the final group fed with a diet having high calcium content, considered as high calcium group. The low calcium diet supplied with $0.25 \%$ of calcium in the diet and the high calcium group supplied with $1 \%$ of calcium in the diet expressed in $\mathrm{mg} \mathrm{Ca/g}$ dry mass. The detailed compositions of the diets were mentioned in our previous study [9]. The experimental diets were isocaloric in nature and differ only in calcium level. The period of dietary treatment was 3 months. Body weight of the rats was recorded weekly during the entire period of treatment.

After 3 months, all the rats were fasted overnight and euthanized the next day following the Indian Council of Medical Research (ICMR) guidelines on animal sacrifice. The liver was collected from each rat, weighed immediately, and kept at $-80^{\circ} \mathrm{C}$ for future experimental studies. Blood was collected through cardiac puncture from each animal for biochemical analysis.

\section{Biochemical analysis of blood}

Liver enzymes alanine transaminase (ALT), aspartate transaminase (AST), and alkaline phosphatase (ALP) were assayed by the colorimetric method using commercial kits (Erba, Mannheim) in semi-auto-analyzer. Plasma C-reactive protein (CRP) level was estimated using the enzymelinked immunosorbent assay (ELISA) kit in microplate reader according to the protocol provided with the kit (Ray Biotech, USA).

Preparation of liver tissue homogenate for antioxidant and oxidative assay

A $5 \%(\mathrm{~W} / \mathrm{V})$ tissue homogenate of liver tissue was prepared in ice-cold $50 \mathrm{mM}$ phosphate buffer $(\mathrm{pH}=7.0)$ containing $0.1 \mathrm{mM}$ ethylenediaminetetraacetic acid (EDTA) using Potter-Elvehjem glass homogenizer. The homogenates were centrifuged (Sigma Laborzentrifugen, Germany) at $10,000 \mathrm{rpm}$ for $20 \mathrm{~min}$ at $4^{\circ} \mathrm{C}$. After the centrifugation; the supernatant was collected and used for catalase (CAT), superoxide dismutase (SOD), and protein carbonyl content (PCO). For lipid peroxidation assay, a $10 \%(\mathrm{~W} / \mathrm{V})$ of liver tissue homogenate was prepared in $1.5 \% \mathrm{KCl}$.

\section{Antioxidant assay from plasma and liver sample}

CAT (EC: 1.11.1.6) activity was determined by adding $50 \mu \mathrm{l}$ of sample was added to a cuvette containing $2 \mathrm{ml}$ of phosphate buffer ( $\mathrm{pH} 7.0)$ and $1 \mathrm{ml}$ of $30 \mathrm{mM}$ hydrogen peroxide $\left(\mathrm{H}_{2} \mathrm{O}_{2}\right)$. CAT activity was measured spectrophotometrically (Spectroquant Pharo 300, Merck, Germany) at $240 \mathrm{~nm}$. CAT activity was expressed as unit/mg of protein [12].

SOD (EC: 1.15.1.1) activity was assayed with slight modification [13]. The final assay mixture of $1 \mathrm{ml}$ consists of $75 \mathrm{mM}$ of Tris- $\mathrm{HCl}$ buffer (pH 8.2), $30 \mathrm{mM}$ EDTA, $2 \mathrm{mM}$ pyrogallol, and at the end $50 \mu \mathrm{l}$ of the sample was added as the enzyme source. The increase in absorbance was recorded spectrophotometrically at $420 \mathrm{~nm}$. One unit of SOD activity is $50 \%$ inhibition of the rate of auto-oxidation of pyrogallol, and the activity is expressed as unit/mg of protein.

Glutathione peroxidase (GPx) (EC: 1.11.1.9) activity was measured from the plasma and tissue homogenate [14]. The final volume consists of $1 \mathrm{ml}, 0.05 \mathrm{M}$ phosphate buffer with $2 \mathrm{mM}$ EDTA, (pH 7.0) $0.025 \mathrm{mM}$ sodium azide, $0.15 \mathrm{mM}$ reduced glutathione, and $0.25 \mathrm{mM} \mathrm{NADPH}$ and $100 \mu \mathrm{l}$ of $5 \%$ tissue supernatant as the enzyme source. The reaction was initiated by the addition of $0.36 \mathrm{mM} \mathrm{H}_{2} \mathrm{O}_{2}$. The linear fall in absorbance at $340 \mathrm{~nm}$ was recorded spectrophotometrically. The specific activity was expressed as nmol of NADPH oxidized/min/mg protein.

\section{Lipid peroxidation assay}

The lipid peroxidation was determined by the thiobarbituric acid (TBA) method by quantifying the formation of malondialdehyde (MDA), an end product of lipid peroxidation [15]. In $1 \mathrm{ml}$ sample, $2.5 \mathrm{ml}$ of $20 \%$ TCA was added and the contents were centrifuged at $3500 \mathrm{~g}$ for $10 \mathrm{~min}$, and the precipitate was dissolved in $2.5 \mathrm{ml}$ of $0.05 \mathrm{M}$ sulfuric acid. To this, $3 \mathrm{ml}$ of TBA was added and the samples were kept in a hot water bath for $30 \mathrm{~min}$. The samples were cooled and MDA was extracted with $4 \mathrm{ml}$ of butanol and the pink color developed was determined spectrophotometrically at $530 \mathrm{~nm}$ and expressed MDA as the $\mathrm{nmol} / \mathrm{mg}$ of protein or $\mathrm{nmol} / \mathrm{ml}$.

\section{Estimation of PCO}

Briefly, $200 \mu \mathrm{l}$ of the sample was added to plastic tubes containing $400 \mu \mathrm{l}$ of $10 \mathrm{mM}$ dinitrophenylhydrazine (prepared in $2 \mathrm{M} \mathrm{HCl}$ ). Subsequently, $500 \mu \mathrm{l}$ of $20 \%$ TCA was added to each tube. The mixture was vortexed and centrifuged at 14,000 g for $3 \mathrm{~min}$ and the supernatant obtained was discarded. The pellet was washed with $1 \mathrm{ml}$ ethanol/ethyl acetate $(1: 1 \mathrm{v} / \mathrm{v})$, vortexed and centrifuged at $14,000 \mathrm{~g}$ for $3 \mathrm{~min}$. The supernatant was then discarded and the pellet-suspended in $600 \mu \mathrm{l}$ of $6 \mathrm{M}$ guanidine (prepared in a $20-\mathrm{mM}$ potassium phosphate solution, $\mathrm{pH}$ 2.3), vortexed and incubated at $60^{\circ} \mathrm{C}$ for $15 \mathrm{~min}$. Samples were then centrifuged at 14,000 g for $3 \mathrm{~min}$ and the supernatant used to measure absorbance at $370 \mathrm{~nm}$ and reported PCO the in $\mathrm{nmol} / \mathrm{mg}$ protein or $\mathrm{nmol} / \mathrm{ml}[16]$.

\section{Protein determination}

Protein quantification from plasma and tissue homogenates was carried out by the Lowry method using serum albumin as standard [17].

\section{Plasma inflammatory markers}

Pro-inflammatory cytokines as IL- 6 and TNF- $\alpha$ were measured from the plasma using ELISA kits (Abcam, USA) according to manufacturer protocol in a microplate reader. All the samples were done in duplicate.

\section{Histological study}

The liver was gently washed in phosphate-buffered saline and subjected to fixation in $10 \%$ neutral buffered formalin and thereafter further processing was done which includes dehydration and infiltration followed by embedding in paraffin. Then, $5(\mu \mathrm{m})$ sections of the paraffin block were obtained using a microtome and taken for staining with Hematoxylin-Eosin (H\&E) stain. The pictures of stained slides were obtained under a microscope (Leica DM400 BLED, Germany) under $\times 40$ magnification.

\section{Statistical analysis}

The results were presented as means \pm standard error mean. The differences between the means of groups were analyzed by one-way ANOVA followed by Tukey HSD post hoc test using Statistical Package for the Social Sciences 16.0 for Windows. Statistical significance was considered at $\mathrm{p}<0.05$.

\section{RESULTS}

\section{Effect of dietary calcium on body and liver weight}

The final body weight was significantly increased $(p<0.01$, Fig. $1 a)$ in the low calcium diet fed rats as compared to the control group, while the final body weight was significantly decreased $(p<0.05$, Fig. $1 \mathrm{a})$ in high calcium diet fed rats as compared to the control group. The weight of the liver was significantly increased $(p<0.05$, Fig. $1 b)$ in low calcium fed rats as compared to the other two groups at the end of the study.

Effect of dietary calcium on plasma inflammatory markers (IL-6 and TNF- $\alpha$ )

The plasma inflammatory marker such as the IL- 6 and TNF- $\alpha$ was significantly increased ( $<<0.05$, Fig. 2 ) in the low calcium fed rats as compared to the control, while the inflammatory markers within the plasma level were low in the high calcium group but did not reach the significance level compared to the control group in Fig. 2.

\section{Effect of dietary calcium on blood biochemical parameters}

The hepatic enzymes ALT, AST, and ALP activities were significantly increased $(p<0.05$, Table 1$)$ in low calcium fed rats as compared to the 


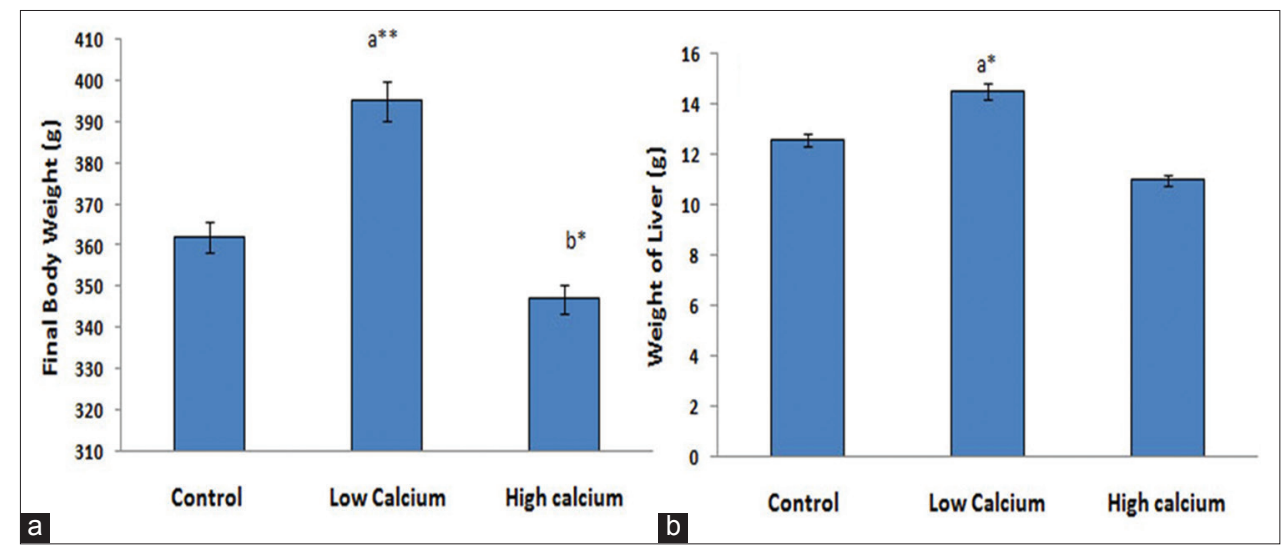

Fig. 1: Final body weight and liver weight. Values represent mean \pm standard error mean of 10 rats in each group; (a) low calcium versus control; (b) high calcium versus control. Significant level; ${ }^{*} \mathbf{p}<0.05$; ${ }^{* *} \mathbf{p}<0.01$

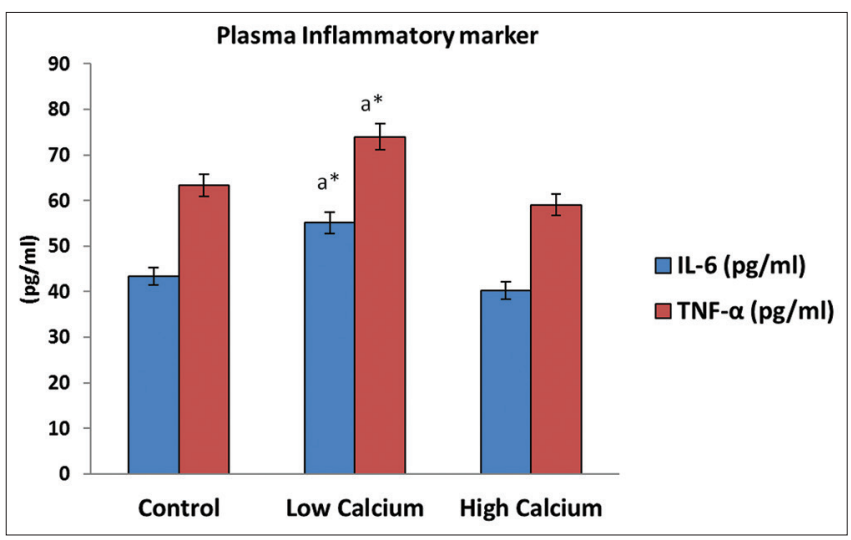

Fig. 2: Plasma inflammatory markers. Values represent mean \pm standard error mean of 10 rats in each group; (a) low calcium versus control; (b) high calcium versus control. Significant level; *p $<0.05 ;{ }^{* *} \mathbf{p}<0.01$

Table 1: Biochemical parameters from plasma

\begin{tabular}{llll}
\hline Blood parameters & Control & Low calcium & High calcium \\
\hline ALT $(\mathrm{U} / \mathrm{L})$ & $45.82 \pm 2.64$ & $48.07 \pm 2.95^{\mathrm{a}}$ & $44.84 \pm 2.23$ \\
AST $(\mathrm{U} / \mathrm{L})$ & $33.92 \pm 1.34$ & $37.29 \pm 1.72^{\mathrm{a} *}$ & $33.12 \pm 1.29$ \\
ALP $(\mathrm{U} / \mathrm{L})$ & $147.92 \pm 7.71$ & $163.44 \pm 8.16^{\mathrm{a} *}$ & $145.41 \pm 6.57$ \\
CRP $(\mu \mathrm{g} / \mathrm{ml})$ & $2.08 \pm 0.03$ & $3.49 \pm 0.06^{\mathrm{a} *}$ & $1.88 \pm 0.03$ \\
\hline
\end{tabular}

Values represent mean \pm standard error mean of 10 rats in each group; (a) low calcium versus control; (b) high calcium versus control. Significant level; ${ }^{*} \mathrm{p}<0.05 ; * \mathrm{p}<0.01$. ALT: Alanine transaminase, AST: Aspartate transaminase, ALP: Alkaline phosphatase, CRP: C-reactive protein

control group at the end of the study. On the other hand, the level of plasma inflammatory marker CRP was significantly increased ( $p<0.05$, Table 1) in low calcium fed rats as compared to the control group. However, these liver function and inflammatory parameters did not show any significant changes in high calcium group compared to the control group in Table 1.

Effect of dietary calcium on plasma and hepatic oxidative stress parameters

The plasma and hepatic lipid peroxidation products MDA were significantly increased ( $\mathrm{p}<0.05$, Fig. 3a and $\mathrm{c}$ ) in low calcium fed rats as compared to the control group. The plasma and hepatic PCO was significantly increased ( $p<0.05$, Fig. $3 b$ and $d$ ) in low calcium fed rats as compared to control group. On the other hand, the oxidative markers within the hepatic as well as blood in high calcium fed rats did not show any significant changes compared to the control group.
Effect of dietary calcium on plasma and hepatic antioxidant parameters

The plasma and hepatic antioxidant enzyme activities such as SOD and GPx were significantly decreased $(\mathrm{p}<0.05$, Table 2$)$ in low calcium fed rats as compared to the control group. On the other hand, the antioxidant markers within the hepatic tissue as well as blood in high calcium fed rats did not show any significant changes compared to the control group. There is no such significant change in the plasma and hepatic CAT activity between the three groups at the end of the study (Table 2).

\section{Effect of dietary calcium on histological analysis of liver}

Histopathological study of liver tissue was carried out by H\&E staining from three groups and showed in Fig. 4. The morphological analysis of low calcium fed rats showed some pathological alterations like the swelling of hepatocytes which are marked by arrows. On the other hand, there was no such pathological alteration observed in the control and high calcium group reserving the normal physiological architecture of the hepatocytes.

Histological examination of liver tissue was carried out by H\&E staining, and the microscopic images were viewed under $\times 40$ magnification (scale bar $=50 \mu \mathrm{m}$ ). The black arrow bar shows the swelling of hepatocytes and subsequent injuries, while the other two groups showed the normal histological architecture of hepatocytes.

\section{DISCUSSION}

Obesity increases the body fat content and body weight gain, which is associated with several health hazards, thereby reducing the life expectancy [4]. Treatment of obesity is time consuming and considered to be a complicated process with no easy solutions. In spite of several efforts by various medical professionals, it is still difficult to prevent the progress of obesity and its related metabolic complications. Most of the anti-obesity drugs presently in practice are found to have one or other undesirable side effect. Therefore, recently, alternative medicines through dietary interventions are gaining prominence to deal with obesity [18]. In the present study, we observed that prolonged intervention with different types of energy-restricted calcium diet regulated the body weight and liver weight suggesting an inverse relationship between calcium intake and anthropometric markers of obesity conforming to the findings of various previous studies $[3,9]$. Studies linking poor calcium nutrition and excess body weight have been reported in different species. In rodent models, low dietary calcium has been implicated in weight gain, and calcium supplementation has been shown to prevent it [19]. In our previous study, we observed that dietary calcium-regulated fat accumulation by altering the lipogenesis and the lipolysis pathway. The alteration in the lipid metabolism within the adipocyte was found to be associated with adipocyte hypertrophy commonly observed during obesity [9]. 
Table 2: Plasma and hepatic antioxidant parameters

\begin{tabular}{llll}
\hline Sample type & Antioxidant parameters & Control & Low calcium \\
\hline Plasma sample & CAT (U/mg of protein) & $0.323 \pm 0.017$ & $0.286 \pm 0.015$ \\
& SOD (U/mg of protein) & $5.03 \pm 0.17$ & $4.73 \pm 0.14^{\mathrm{a} *}$ \\
Hepatic sample & GPx (nmol/min/mg of protein) & $17.7 \pm 2.78$ & $15.91 \pm 2.57^{\mathrm{a} *}$ \\
& CAT (U/mg of protein) & $2.13 \pm 0.20$ & $1.74 \pm 0.08$ \\
& SOD (U/mg of protein) & $10.95 \pm 0.28$ & $8.13 \pm 0.21^{\mathrm{a} *}$ \\
\hline
\end{tabular}

Values represent mean \pm standard error mean of 10 rats in each group; (a) low calcium versus control, (b) high calcium versus control. Significant level; ${ }^{*}<<0.05$;

${ }^{* *} \mathrm{p}<0.01$. CAT: Catalase, SOD: Superoxide dismutase, GPx: Glutathione peroxidase

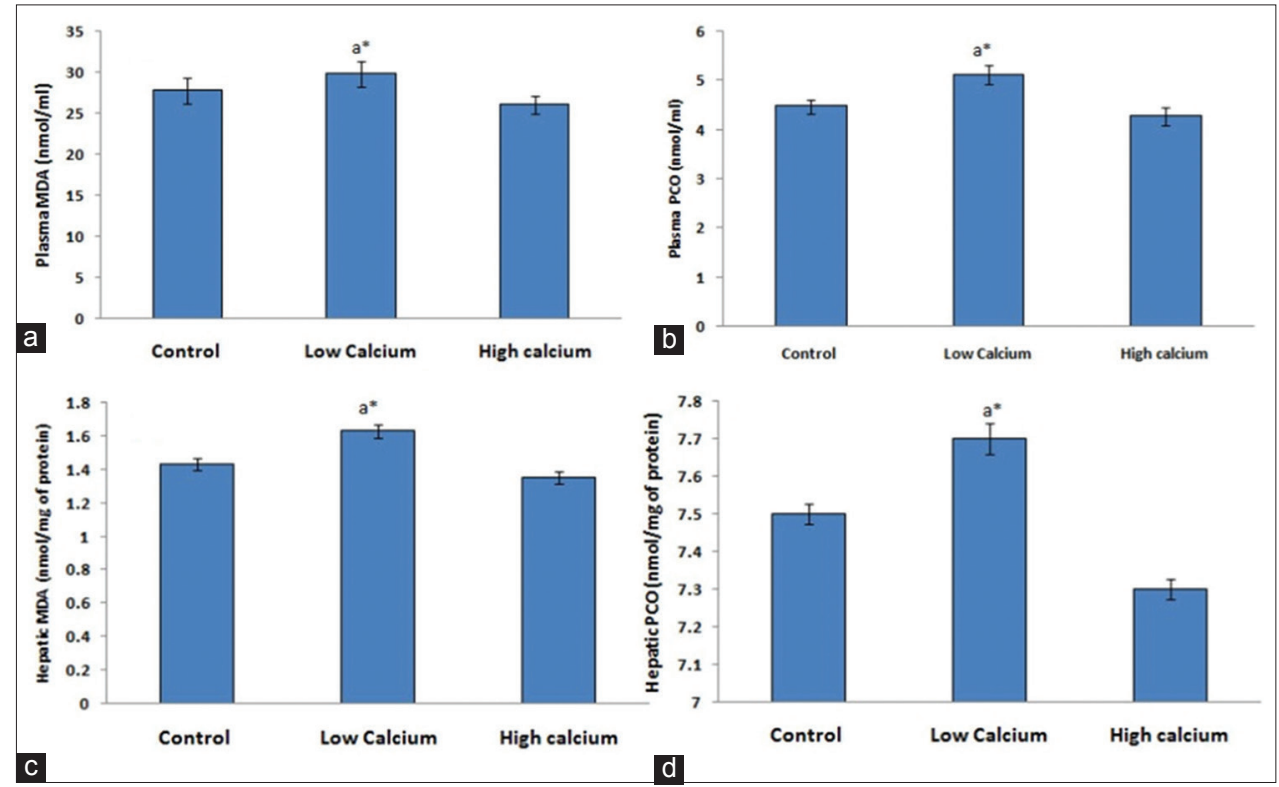

Fig. 3: Oxidative stress parameters from plasma and hepatic tissue. (a) Plasma malondialdehyde (MDA), (b) plasma protein carbonyl content (PCO), (c) hepatic MDA, and (d) hepatic PCO. Values represent mean \pm standard error mean of 10 rats in each group; (a) low calcium versus control; (b) high calcium versus control. Significant level; ${ }^{*} \mathbf{p}<0.05 ;{ }^{* *} \mathbf{p}<0.01$

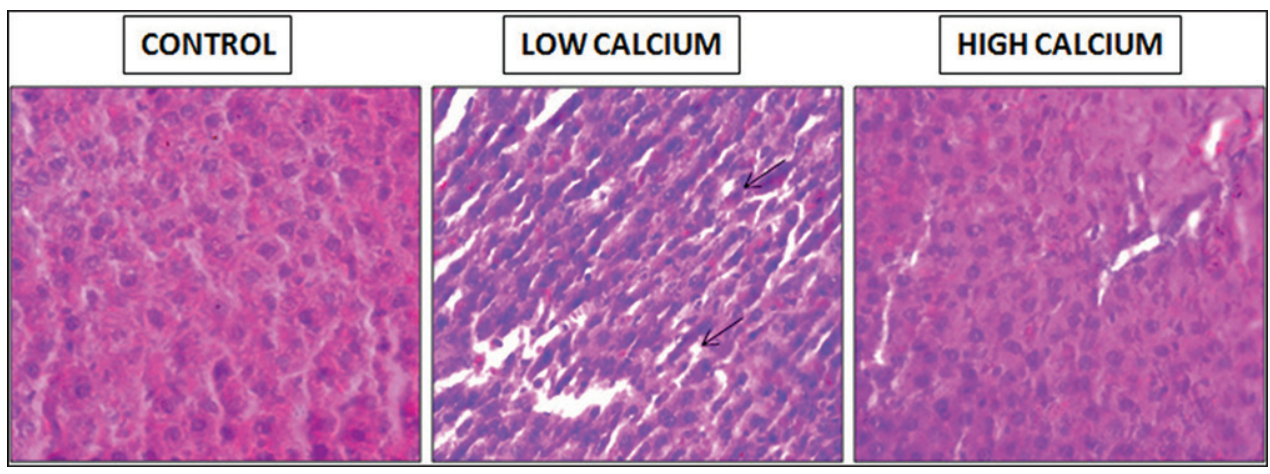

Fig. 4: Histopathological examination of liver tissue

Adipocyte hypertrophy during obesity triggers a state of low-grade chronic inflammation, frequently referred to as systemic inflammation or metabolic inflammation. These inflammatory changes further promote the development of several metabolic diseases, including NAFL disease (NAFLD). Reports suggested that adipose tissue is a critical source of inflammation in obesity and causally involved in NAFLD progression. However, it is unclear whether suppression of adipose tissue inflammation would attenuate NAFLD progression or not [20].

In the present study, we observed that the plasma inflammatory markers IL- 6 and TNF- $\alpha$ were increased in low calcium fed rats. The increase in plasma inflammatory markers in dietary calcium deprived rats might have resulted from increased secretions of cytokines from hypertrophied adipose tissue through macrophage infiltration [21]. Elevated TNF- $\alpha$ is associated with elevations in circulating free fatty acid levels derived from enlarged adipocytes through lipolysis. It stimulates the hepatic lipogenesis pathway causing lipid accumulation and risk of IR which is associated with obesity [22]. IL-6 increases the hepatic lipogenesis activity and thereby promotes hepatic lipid accumulation and increases the risk of fatty liver diseases [23]. In our present study, low dietary calcium might have contributed to both by increasing both IL- 6 and TNF- $\alpha$ level. On the other hand, high calcium in diet in our study reduced the level of plasma inflammatory markers and prevented the state of low-grade inflammation preventing the deleterious effect. The similar beneficial effect of high calcium diet was observed in transgenic obese mice. Exposure to high calcium diet in 
obese mice prevented body weight gain and adiposity and also inhibited the expression of TNF- $\alpha$ and IL- 6 . At the same time, it resulted in the elevation of anti-inflammatory factors such as IL-5 and adiponectin within visceral fat as well as in plasma, thereby preventing the adverse effects of obesity $[24,25]$.

Obesity-induced inflammation is frequently associated with oxidative stress. The excess secretion of TNF- $\alpha$ and IL- 6 from enlarged adipocytes stimulates the enzymatic activity of NADPH oxidase, nuclear factor- $\kappa \beta$ activation, and induce hyperglycemia which altogether promotes the production ROS and induce oxidative stress during obese condition [26]. In our present study, we observed that the plasma and hepatic MDA and PCO increased in low calcium diet fed rats resulting in oxidative stress by upregulating the lipid peroxidation and protein carbonylation activity. During oxidative stress, the generation of free radicals adversely affects cell survival due to membrane damage by oxidation of lipid, protein, and irreversible modification of DNA [27]. Lipid peroxidation such as TBA reactive substances and hydroperoxides levels as well as markers of protein oxidation such as carbonyl proteins is markers of oxidative damage of ROS [27]. The increase in the secretion of TNF- $\alpha$, IL-6, leptin along with the decrease in the secretion of adiponectin from hypertrophic adipocytes found to be associated with hepatic IR, inflammation, and oxidative stress [8]. ROS and lipid peroxidation products affect the hepatocyte respiratory chain either directly or indirectly through oxidative damage to the mitochondrial genome. This leads to the production of more ROS and a vicious cycle ensues. Hepatic mitochondrial dysfunction can lead to apoptosis or necrosis depending on the energy status of the cell. Finally, ROS and lipid peroxidation activate the hepatic stellate cells inducing fibrosis [28]. Histopathological analysis of liver in our low calcium fed rats showed that there is an accumulation of lipid droplets and, on the other hand, the reversed effect was shown by high calcium diet showing normal physiological hepatic architecture. Similar morphological alteration such as hepatic lipid accumulation in the form of lipid droplets and swelling of hepatocytes was observed in diet-induced obese rats [29].

Animal body possessed an effective mechanism to prevent the free radical-induced tissue cell damage, through a series of endogenous antioxidant enzymes and protein such as glutathione s transferase, SOD, CAT, GPx, and reduced glutathione. When the physiological balance between ROS generation and antioxidant defense is diminished the oxidative stress occurs; causing several of cellular events that deregulate the cellular functions leading various pathological conditions [30]. The superoxide anion is a peroxidative molecule which is scavenged by SOD converting superoxide anion into $\mathrm{H}_{2} \mathrm{O}_{2}$ which is again removed by another antioxidant enzyme GPx. GPx, on the other hand, tries to maintain the $\mathrm{H}_{2} \mathrm{O}_{2}$ concentration within the physiological condition even after the stimulation of oxidative stress [27]. The reduced level of plasma and hepatic SOD and GPx activities in our low calcium fed rats failed to suppress the toxic effect of oxidative stress. The oxidative stress induced hepatic injury in low calcium fed rats may have increased the plasma levels of hepatic enzymes such as ALT, AST, and ALP. The alteration in the secretion of hepatic enzymes from injured hepatocytes into blood circulation is commonly observed in a hepatic disorder like NAFLD, which is commonly associated with obesity [31]. Moreover, many recent studies have shown that fatty liver is associated with cardiovascular disease, kidney disease, colon cancer, and osteoporosis [32]. Further, the rise in serum CRP level in low calcium diet confirms the hepatic injury as a result of oxidative stress. The rise in liver enzymes was closely related to higher CRP concentrations. Hepatic inflammation and oxidative stress, as a result of steatosis is a potential contributor to the low-grade inflammation associated with obesity-related metabolic syndrome [33]. On the other hand, high calcium diet non significantly reduced the serum CRP level, which may be associated with the systemic inflammation during obese condition [34]. On the other hand, high calcium diet prevents oxidative stress by restoring the antioxidant level within the hepatocytes and plasma. The beneficial effect of a high calcium diet against the hepatic oxidative stress by restoring the antioxidant level and reducing the steatosis was observed in obese adult rats which were overfed during lactation [35]. Hence, the accumulation of abdominal fat not only induces obesity-related inflammation as well as IR [36] but also modulates the hepatic physiological functions which are closely associated with obesity-related inflammatory response. Hence, the adequate amount of dietary mineral supplements like calcium seemed to be effective in preventing the risk of liver damage by maintaining the physiological balance between ROS and antioxidant level.

\section{CONCLUSION}

The present study showed that low calcium diet on pro-longed consumption stimulates the production of adipose-derived inflammatory markers such as IL- 6 and TNF- $\alpha$ into the blood circulation and at the same time it is associated with oxidative stress within hepatocytes and plasma which is prevented by high calcium in the diet. Considering the potential role of dietary calcium against oxidative stress and inflammation further studies are required to understand the role of dietary calcium on different signaling pathway to prevent the risk of metabolic complications associated with obesity.

\section{ACKNOWLEDGMENTS}

Financial support for the project by ICMR, New Delhi is acknowledged (5/7/1213/2014-RCH Dated: February 18, 2015).

\section{CONTRIBUTION OF AUTHORS}

SD and DC designed the study. SD performed the experiments. SD and DC analyzed, interpret the data and wrote the manuscript. DC was the supervisor of this experiment and revised the article critically for important intellectual content. All the authors read and approved the final manuscript.

\section{CONFLICTS OF INTEREST STATEMENT}

Authors declare that there are no conflicts of interest.

\section{REFERENCES}

1. Popkin BM, Gordon-Larsen P. The nutrition transition: Worldwide obesity dynamics and their determinants. Int J Obes Relat Metab Disord 2004;28 Suppl 3:S2-9.

2. Via M. The malnutrition of obesity: Micronutrient deficiencies that promote diabetes. ISRN Endocrinol 2012;2012:103472.

3. Schrager S. Dietary calcium intake and obesity. J Am Board Fam Pract 2005;18:205-10.

4. Peixoto TC, Moura EG, de Oliveira E, Soares PN, Guarda DS, Bernardino DN, et al. Cranberry (Vaccinium macrocarpon) extract treatment improves triglyceridemia, liver cholesterol, liver steatosis, oxidative damage and corticosteronemia in rats rendered obese by high fat diet. Eur J Nutr 2018;57:1829-44.

5. Gregor MF, Hotamisligil GS. Thematic review series: Adipocyte biology. Adipocyte stress: The endoplasmic reticulum and metabolic disease. J Lipid Res 2007;48:1905-14.

6. Jo J, Gavrilova O, Pack S, Jou W, Mullen S, Sumner AE, et al. Hypertrophy and/or hyperplasia: Dynamics of adipose tissue growth. PLoS Comput Biol 2009;5:e1000324.

7. Fernández-Sánchez A, Madrigal-Santillán E, Bautista M, EsquivelSoto J, Morales-González A, Esquivel-Chirino C, et al. Inflammation, oxidative stress, and obesity. Int J Mol Sci 2011;12:3117-32.

8. Sacerdoti D, Singh SP, Schragenheim J, Bellner L, Vanella L, Raffaele M, et al. Development of NASH in obese mice is confounded by adipose tissue increase in inflammatory NOV and oxidative stress. Int J Hepatol 2018;2018:1-14.

9. Das S, Choudhuri D. Role of low calcium and high calcium diet on adipocyte metabolism with respect to serum parathyroid hormone (PTH) levels in male Wistar rats. Indian J Physiol Pharmacol 2017;61:430-9.

10. Aslam MN, Bassis CM, Zhang L, Zaidi S, Varani J, Bergin IL, et al. Calcium reduces liver injury in mice on a high-fat diet: Alterations in microbial and bile acid profiles. PLoS One 2016;11:e0166178.

11. dos Santos LC, de Pádua Cintra I, Fisberg M, Martini LA. Calcium intake and its relationship with adiposity and insulin resistance in postpubertal adolescents. J Hum Nutr Diet 2008;21:109-16. 
12. Aebi H. Catalase in vitro. Methods Enzymol 1984;105:121-6.

13. Marklund S, Marklund G. Involvement of the superoxide anion radical in the autoxidation of pyrogallol and a convenient assay for superoxide dismutase. Eur J Biochem 1974;47:469-74.

14. Paglia DE, Valentine WN. Studies on the quantitative and qualitative characterization of erythrocyte glutathione peroxidase. J Lab Clin Med 1967:70:158-69.

15. Ohkawa H, Ohishi N, Yagi K. Assay for lipid peroxides in animal tissues by thiobarbituric acid reaction. Anal Biochem 1979;95:351-8.

16. ReznickAZ, PackerL. Oxidative damage to proteins: Spectrophotometric method for carbonyl assay. Methods Enzymol 1994;233:357-63.

17. Lowry OH, Rosebrough NJ, Farr AL, Randall RJ. Protein measurement with the folin phenol reagent. J Biol Chem 1951;193:265-75.

18. Panchal SK, Ward L, Brown L. Ellagic acid attenuates highcarbohydrate, high-fat diet-induced metabolic syndrome in rats. Eur J Nutr 2013;52:559-68.

19. Villarroel P, Villalobos E, Reyes M, Cifuentes M. Calcium, obesity, and the role of the calcium-sensing receptor. Nutr Rev 2014;72:627-37.

20. Mulder P, Morrison MC, Verschuren L, Liang W, van Bockel JH, Kooistra T, et al. Reduction of obesity-associated white adipose tissue inflammation by rosiglitazone is associated with reduced non-alcoholic fatty liver disease in LDLr-deficient mice. Sci Rep 2016;6:31542.

21. Wisse BE. The inflammatory syndrome: The role of adipose tissue cytokines in metabolic disorders linked to obesity. J Am Soc Nephrol 2004; $15: 2792-800$

22. Cheung AT, Ree D, Kolls JK, Fuselier J, Coy DH, Bryer-Ash M, et al. An in vivo model for elucidation of the mechanism of tumor necrosis factor-alpha (TNF-alpha)-induced insulin resistance: Evidence for differential regulation of insulin signaling by TNF-alpha. Endocrinology 1998; 139:4928-35

23. Brass EP, Vetter WH. Interleukin-6, but not tumour necrosis factoralpha, increases lipogenesis in rat hepatocyte primary cultures. Biochem J 1994;301 (Pt 1):193-7.

24. Sun X, Zemel MB. Calcium and 1,25-dihydroxyvitamin D3 regulation of adipokine expression. Obesity (Silver Spring) 2007;15:340-8.

25. Zemel MB, Sun X. Dietary calcium and dairy products modulate oxidative and inflammatory stress in mice and humans. J Nutr 2008; $138: 1047-52$
26. Huang CJ, McAllister MJ, Slusher AL, Webb HE, Mock JT, Acevedo EO, et al. Obesity-related oxidative stress: The impact of physical activity and diet manipulation. Sports Med Open 2015;1:32.

27. Noeman SA, Hamooda HE, Baalash AA. Biochemical study of oxidative stress markers in the liver, kidney and heart of high fat diet induced obesity in rats. Diabetol Metab Syndr 2011;3:17.

28. Carmiel-Haggai M, Cederbaum AI, Nieto N. A high-fat diet leads to the progression of non-alcoholic fatty liver disease in obese rats. FASEB J 2005;19:136-8.

29. Rameshreddy P, Uddandrao VV, Brahmanaidu P, Vadivukkarasi S, Ravindarnaik R, Suresh P, et al. Obesity-alleviating potential of asiatic acid and its effects on ACC1, UCP2, and CPT1 mRNA expression in high fat diet-induced obese sprague-dawley rats. Mol Cell Biochem 2018;442:143-54.

30. Manna P, Jain SK. Obesity, oxidative stress, adipose tissue dysfunction, and the associated health risks: Causes and therapeutic strategies. Metab Syndr Relat Disord 2015;13:423-44

31. Vincent HK, Powers SK, Dirks AJ, Scarpace PJ. Mechanism for obesity-induced increase in myocardial lipid peroxidation. Int J Obes Relat Metab Disord 2001;25:378-88.

32. Abozid MM, Zein H, El-Halem AA. Effect of common carp and African catfish oils on rats fed on high-fat diet. Int J Pharm Pharm Sci 2018;10:96-101.

33. Kerner A, Avizohar O, Sella R, Bartha P, Zinder O, Markiewicz W, et al. Association between elevated liver enzymes and C-reactive protein: Possible hepatic contribution to systemic inflammation in the metabolic syndrome. Arterioscler Thromb Vasc Biol 2005;25:193-7.

34. Fronczyk A, Moleeda P, Safranow K, Piechota W, Majkowska L. Increased concentration of C-reactive protein in obese patients with Type 2 diabetes is associated with obesity and presence of diabetes but not with macrovascular and microvascular complications or glycemic control. Inflammation 2014;37:349-57.

35. Conceição EP, Moura EG, Soares PN, Ai XX, Figueiredo MS, Oliveira $0 \mathrm{E}$, et al. High calcium diet improves the liver oxidative stress and microsteatosis in adult obese rats that were overfed during lactation. Food Chem Toxicol 2016;92:245-55.

36. Sapkota NK. Modifiable risk factors of prediabetes. Innovare J Med Sci 2017;5:1-2. 